\title{
INFLUENCE OF CULTURE ON STUDENTS' AWARENESS OF HOW AND WHY THEY LEARN
}

\author{
${ }^{1}$ Siew Chee Choy, ${ }^{2}$ Daljeet Singh Sedhu, ${ }^{3}$ Yow Lin Liew, \\ ${ }^{4}$ Mun Yee Lee, ${ }^{5}$ Audrey Malenee \& ${ }^{6}$ Norkhadirah Anuar \\ ${ }^{1-6}$ Centre for Educational Psychology and Instructional Strategies \\ Tunku Abdul Rahman University College
}

${ }^{1}$ Corresponding author: choysc@mail.tarc.edu.my

\begin{abstract}
Purpose - The reason many Asian students find student-centred learning challenging may be due to cultural factors present in every human interaction between individuals. This study attempts to determine the influence of these cultural factors on students' awareness of how and why they learn.
\end{abstract}

Method - A sample of 12 students enrolled in a two year diploma course in a Malaysian university was interviewed, using a semistructured interview protocol, on the students' perceptions and experiences when learning. The results were analysed qualitatively using the interpretive approach.

Findings - The results show that students rely on their teachers for information, implying a high power distance as well as low individualism, and are not inclined to explore on their own. These students readily approach their friends rather than teachers for help with their assignments. They also hold their parents' opinions in high regard.

Significance - The results of this study are important for teachers when implementing student-centred learning. It will be challenging for Malaysian students to respond well to this form of learning strategy as it requires a certain amount of independent learning as well as risk-taking behaviour which these students seem to lack. 
Keywords: Cultural influences, student learning, perceptions and learning experience.

\section{INTRODUCTION}

Many classrooms today have implemented outcome-based learning and student-centred learning. In these types of learning, students play a pivotal role during the learning process. However, even with such learner-oriented strategies, students still experience difficulties when learning. Studies have found that the culture students belong to influences the manner in which they learn and interact in the classroom (Kember \& Wong, 2000; Kember, 2009; Hiew, 2012). The word 'culture' in this context, refers to the collective patterned way of thinking which distinguishes one group of individuals from another (Hofstede, 2001). This study is interested to know how Malaysian students exhibit the influences of culture as defined by Hofstede (1984) while they are learning.

These collective ways of thinking result in forming cultural factors which, to a certain extent, determine how individuals live and socialise (Zion \& Kazleski, 2005). Learning from a constructivist view (Vygotsky, 1986) is social in nature and therefore is influenced by the culture of an individual. Hence, cultural factors can influence the way an individual learns. These factors, initially thought to be present in every interaction between individuals and confined to race and ethnicity, are actually a more complex weave in all cultural groups and influence values, beliefs and behaviours of individuals (Zion \& Kazleski, 2005). Therefore cultural factors can be viewed as preferences that are strongly embedded in individuals because of the highly social nature of humans and their strong need to fit into social groups (Parrish \& Linder-VanBerschot, 2010).

\section{Influence of Culture on Learning}

Human culture is the result of human programming which occurs mainly before puberty and is strongly influenced by the immediate family and the educational environments of individuals. According to Hofstede (2007), culture is the collective programming of the mind that distinguishes one group of individuals from another and tends 
to affect deeply embedded beliefs. Unlike human nature, which is inherited, culture is learned (Parrish \& Linder-Van Berschot, 2010). Although human nature and culture have extensive influences, they do not predict how individuals will respond to situations.

According to Ginsberg (2005), the response individuals have to a learning activity reflects their ethnic and cultural backgrounds. Hence, cognitive processes may be regarded as inherently cultural. Hofstede, Hofstede \& Minkov (2010) note that different cultural values between students and their teachers can become a source of problems which can hinder the process of learning. Adding to these difficulties are the different expectations of societies (Hofstede, et al., 2010). This is especially true if the teacher has a western perspective of education where students are expected to speak up and give opinions. However, from the Asian students' perspective, it is improper to speak up if not spoken to directly by the teacher (Hofstede et al., 2010) as they conceive themselves as part of a group. The idea among members of a group is not to stand out but blend in. Students in Malaysia perceive themselves as collectivist according to Hofstede et al. (2010); hence, it makes more sense for individuals to act as part of the group. This makes implementing student-centred learning challenging as it requires each individual to voice his or her own thinking and opinions.

The family dynamics of the students in a collectivist culture will also continue in school with in-group and out-group distinctions (Hofstede, 2007). Hence, in a collectivist classroom, the virtues of harmony and maintaining face are very important for a proper learning environment. Invoking the group's honour is a way of controlling students and shaming is most effective in such environments to correct misbehaviour. Learning in a collectivist society is different from an individualistic one. In an individualistic society, learning is not about how to do but about how to learn as learning is viewed as one that is on-going and life-long. In contrast, a collectivist society views learning as a one-time thing about how to $d o$ in order to adapt to society. This could account for the extensive use of rote learning and reliance on the teacher to impart knowledge (Biggs, 1999) among Asian students, specifically Malaysians. Hence in Asian students' minds, learning is about how to get on in life, a one-time thing rather than life-long learning. 


\section{Hofstede's Cultural Dimensions}

According to Hofstede's (1984) theory of cultural dimensions, humans in different cultures have deeply embedded beliefs and values in their ways of reacting to their environment and may be divided into five cultural dimensions. They are the power distance index, individualism, masculinity, avoidance index and long-term orientation (Minkov \& Hofstede, 2010).

In short, the cultural dimensions are a means of describing a generalisable framework of dealing with a society's pattern of living (Kluckhohn, 1962). These cultural patterns can become extremely stable over time (Hofstede, 2001); hence, as individuals in a culture become exposed to more changes, there are still residual cultural differences that modernisation of a society cannot entirely wipe out. In Malaysia, there is still the collectivist tendency to be integrated from birth into strong cohesive in-groups (Hofstede, 2001). Previous studies have also found that there is greater tendency for collectivist societies to be non-confrontational and to have value conformity (Noordin \& Jusoff, 2010, Kuhnen et al., 2001). Hence, introducing lifelong learning and independent learning into university classrooms is challenging as it requires students to learn independently, be self-directed and open to taking risks. Malaysian students are often classified as passive and reluctant to voice their opinions (Littlewood, 2001; Khoo, 2003; Ahmand \& Sahbak, 2009; Hiew, 2012) which add to the challenges of changing their mind-sets.

Culture in this study is defined using the four cultural dimensions by Hofstede (1984):

1. Individualism (IDV) - as a characteristic of culture, opposes collectivism. Individualist cultures primarily look after their own interest and that of their immediate families. In contrast, collectivist cultures assume that individuals - through births or other means - belong to one or more close groups from which they cannot detach themselves. Life is a matter of survival which is the opposite of individualist groups who view it as hedonistic.

2. Power Distance Index (PDI) - defines the extent to which an individual in a society will tolerate inequality of power and 
consider it as normal. High power distance societies believe that everyone has his/her rightful place, and there is existential inequality in the form of hierarchy. Hence, when things go wrong, there is a tendency to blame rather than change the system to suit current needs. There is a latent conflict between the powerful and the powerless. The elders in such groups are respected and feared.

3. Masculinity (MAS) - this is a characteristic of a culture and it opposes femininity. Masculine cultures have very defined roles for the two sexes, with the role of men seen as assertive, ambitious and competitive; while the women are seen to be in a more nurturing role, striving for the non-material things in life. Societies that are masculine see advancement of careers and earning as important. Achievement is seen in terms of ego boosting, wealth and recognition.

4. Uncertainty Avoidance Index (UAI) - this defines the extent to which individuals are made to feel insecure in a situation that they consider unstructured, unclear or unpredictable and the extent to which they will try to avoid such situations by adopting strict codes of behaviour and a belief in absolute truths. There is a need for structure in high uncertainty avoidance societies. This is reflected in schools which favour structured learning situations with precise objectives, detailed assignments and strict timetables. Teachers are also expected to be experts who have all the answers.

\section{METHODOLOGY}

A qualitative approach, namely the interpretive approach, was used because this study is about giving voice to students' learning experiences (Larkin, Watts, \& Clifton, 2006). The intention is not to oversimplify the voices of individuals by summarising their opinions but rather to develop them at an interpretive level. This approach required firstly, a highly intensive and detailed analysis of accounts produced by the participants which were captured verbatim and secondly, an in-depth and analytical commentary on their 'sensemaking' activities when learning. 
The view of social-constructivism (Radnor, 2002; Creswell, 2013) was used in the interpretive approach for this study. The comments and perceptions of the participants formed as a result of social interactions with their peers and caretakers (Williams \& Burden, 1997) were of great value in providing evidence of external cultural influences on them when learning.

\section{The Research Questions}

This study attempts to determine the influence of culture on learning among Malaysian students. The two research questions underpinning this study are:

RQ1. How is the influence of culture reflected in Malaysian students when they learn?

RQ2. What are the differences in the influence of culture on high, average and low achieving students?

\section{Participants}

The study was carried out in a university campus in Malaysia with a cohort of 12 students enrolled in two-year diploma programmes. The students were purposively selected based on their achievement levels. Three categories of students were chosen: the high, average and low achievers based on their entry qualifications to the university. These students were required to have at least a minimum of five grade $\mathrm{C}$ passes from the Sijil Pelajaran Menengah (SPM) examinations, the Malaysian equivalent of the Cambridge ' $O$ ' Levels, or a promotion from a certificate course for those with less than five SPM Grade C passes. In this study, high achievers were those students who scored at least nine SPM Grade A's or better; average achievers were those who scored at least five grade C passes; and the low achievers were those that had only three SPM Grade $\mathrm{C}$ passes and had been promoted from the certificate level programmes. The sample consisted of two students from the high achiever group, seven students from the average achiever group and three from the low achiever group, all in their first year diploma programmes. 


\section{Design and Procedure}

Prior to the interview, the students were asked for their informed consent and were told that they could withdraw from the session anytime. They were also told that all data collected would be kept confidential and viewed only by the research team. The students were interviewed using a semi-structured interview protocol, where the questions were focused on their learning experiences from primary until tertiary education. The interview protocol is shown in Table 1. During the interview, the participants were asked to reflect on and describe their feelings about the experiences they had when learning in school and university. The questions were deliberately broad and general so that the participants could construct their own meanings as they recalled their learning experiences.

Evidence for the study was assembled based on the individual views of the participants. They were interviewed in the environment where they studied to better understand the context of the participants. In order to gather data that was rich and meaningful, each interview was recorded and videotaped. Each researcher practiced active listening (Radnor, 2002) in order to encourage the participants to talk freely about their experiences.

\section{Table 1}

\section{Interview Protocol}

\begin{tabular}{ll}
\hline Interview Phase & Interview Questions \\
\hline First Phase & How did you feel having to go to school? \\
(Primary School) & Did you like going to school? \\
& Did you ever feel bored in school? \\
\cline { 2 - 2 } & $\begin{array}{l}\text { When you were in primary school, why did you } \\
\text { think you had to go to school? }\end{array}$ \\
\cline { 2 - 2 }
\end{tabular}

What were your grades like during primary school? All pass? Did you fail any subject/s?

Describe your performance in terms of grades and school activities during primary school.

Did you go for tuition classes? Did you learn better in these classes than in school? Why? 


\begin{tabular}{ll}
\hline Interview Phase & Interview Questions \\
\hline Second Phase & What were your feelings about school when you \\
(Secondary School) $)$ & were in secondary school? \\
& 'I did not like to go to school because....' \\
& $\begin{array}{l}\text { Did you ever get bullied in school or see someone } \\
\text { being bullied? How did that make you feel about } \\
\text { school? }\end{array}$
\end{tabular}

From your current perspective, why do you think you had to go to secondary school?

Did you find the work you had to do difficult?

Did you learn on your own? Go to teachers for help?

Did you have a special group of friends/classmates you went to for help with homework?

Did you only like to socialise with friends?

\begin{tabular}{l}
\hline Interview Phase \\
\hline Third Phase \\
(Tertiary Educa- \\
tion- Education)
\end{tabular}

Interview Questions

Why did you choose to continue your studies after secondary school?

What do you think you will be doing had you not chosen to continue your studies?

I chose the programme I am in because....

After I complete this programme, I will....

Now that you are in a university, are you still studying that same way as you did in secondary school?

Do you think that this is the best way to study?

The greatest barrier to my success is .....

Do you think you need tuition classes for the programme that you are in? Why and why not?

The transcribed interviews were read and reread until common themes appeared. The various themes were then categorised and used to answer the research questions. There is subjectivity to the data analysis and it is acknowledged that the results of this study may only be valid for the Malaysian population. However, it is hoped that the results may still be applicable to other populations with similar cultural influences.

\section{RESULT AND DISCUSSION}

In the analysis, a comparison of the cultural influences was made between the three groups of students. The various categories derived 
from analysis of the data were used to answer the two research questions.

RQ1. How is the influence of culture reflected in Malaysian students when they learn?

\title{
Working individually versus working in groups
}

Eight out of 12 students said they preferred to do their assignments in a group. All of these students had a special group of friends that they went to for help. They also said that they preferred to ask their friends in the group rather than approach their teachers because it was easier to get answers from them. Added to this, they also felt more comfortable asking their friends than their teachers. For instance, MB commented:

\begin{abstract}
"I like to do my assignments with my group of friends that are in the same programme with me. I like to ask my friends rather than going to see my teacher. It is easier to ask them. I can get the answers quickly".
\end{abstract}

The four students who indicated that they preferred studying on their own did so because they had difficulty feeling comfortable in a study group. This loss of a sense of belonging was more prevalent in university than in school. For instance, GT said:

"I prefer to do my assignments on my own because I have difficulty finding a study group. I do not feel that I am able to mix well with my other classmates. If I can find a group that I feel comfortable with, I will join them. I am also a little older than them because I failed one year in another university".

\section{Perceptions of teachers and parents as authorities}

Nine out of 12 students said that they looked to their teachers to give them information on what they needed to learn. These teachers were perceived as elders; hence, were respected as well as feared. They also perceived these teachers helped them pass examinations during 'tuition' classes and valued those who had more 'experience'. For instance, KF said: 


\begin{abstract}
"During my secondary school, I just listened to what the teachers teach and wait for the answers. I then went for tuition after school as I wanted a more experienced teacher. This is so that I can pass my examinations".
\end{abstract}

These students only listened to teachers who knew what they were talking about and would not do their homework assignments if they could get away with it. This showed a latent conflict between the teacher and the student. They also perceived that the teacher was to blame if they failed in their tests. For instance, KS said:

\begin{abstract}
"I will only listen to the teachers that I felt knew what they were talking about. Some of them will give us homework. I will not do them. Then when I failed in my examinations I would tell my parents that the teacher did not teach us properly".
\end{abstract}

All the students said they stayed in school because of their parents. They were afraid to disobey their parents. All of these students were also expected to do well in school. For instance, BR said:

\begin{abstract}
"I did not want to fail in school because I did not want to disappoint my parents. I was expected by my family to pass my examinations. So I did my homework even when I did not feel like it and went for the tuition classes that they arranged".
\end{abstract}

All the students also said that they decided to enrol in a university programme because of parental expectations. The students perceived that they needed to respect the views of their parents and have their parents be proud of them; hence, they wanted to do well in their studies. For instance, HC said:

"I really did not want to study and I wanted to go and find work after secondary school. But my parents insisted that I enrol in this university. It is okay now after a few months. I need to study hard so that my parents can be proud of me". 


\title{
Female versus male teachers
}

Nine out of 12 students did not have a preference for teachers of a particular gender as long as they were knowledgeable and approachable. An important factor that students considered when deciding whether they liked a teacher was the amount of 'tips' or hints the teacher gave before an examination. They were of the opinion that 'good' teachers would do this before examinations. For instance, FB commented:

\begin{abstract}
"It does not matter to me if my teacher was a male or female as long as they know what and how to teach. They also need to give tips before an exam so that it is easier for me to study".
\end{abstract}

\section{Opportunities for careers and jobs}

Eleven of the 12 students were of the opinion that both sexes should be allowed equal opportunities to work and have a career. They did not think that it was important for them to assume male and female roles as both genders could equally share responsibilities. For instance, KK said:

\begin{abstract}
"I think both males and females should be allowed to go out and work and pursue a career. Like my mother works away from home and my father is the one who stay at home to look after us. That is because my mother is more qualified than my father. My father just runs a restaurant while my mother is an executive. So it does not matter if you are male or female - both must work and share the responsibilities of bringing up a family".
\end{abstract}

Eleven out of 12 students perceived that it was important for them to have a job that earned more money for a brighter future. This is considered a masculine trait and differs from their more ambivalent perceptions of the roles of males and females. For instance, BK commented:

"When I finished my SPM, I went out to work and found
that the job of a salesperson was very difficult and I did
not earn much money. I decided to enrol in a university
programme so that I could get a better job in the future". 


\title{
Risk-taking behaviour
}

All these students did not like to take risks. They looked to their teachers for information. Their focus was learning to pass examinations and not exploring and learning on their own. For example, one of the students, SK said:

"I look to my teachers as a source of information and knowledge. I just want to make sure I can avoid making mistakes when I am taking my examinations".

All of them were of the opinion that their teachers needed to give them hints on what to study before an examination. For instance, FB commented:

\begin{abstract}
"A good teacher, in my opinion, would be giving hints on what to study before an examination. I experienced failing my exam once and that was because the teacher did not give me enough tips; so what I studied did not come out in my examinations".
\end{abstract}

These students also perceived that they were getting higher qualifications to secure a better job in future. Hence, they had to pass their examinations well. For instance, BK commented:

\begin{abstract}
"Before enrolling in the university, I was working as a salesperson in a store. The hours were long with little pay. I do not want that kind of work; so I have to pass my exams and get a better job in future".
\end{abstract}

\section{Discussion}

In general, most of the students liked to learn in their individual groups among peers they liked. This implies a tendency towards integration but only into groups that provided peer support as suggested by Noordin and Jusoff (2010) and Kuhnen et al. (2001). All the students also expressed a preference for going to friends for help rather than their teachers whom they perceived as authority figures. This suggests low IDV. This also implies a high PDI towards their teachers, similar to findings by Hofstede (2007). 
However, these students also chose not to follow instructions from the teacher if they perceived they could get away with it, implying the PDI gap may be diminishing, similar to what was found by Ginsberg (2005). However, all of these students, regardless of their backgrounds, respected their parents and allowed them to play a big role in their lives and education. Many of these students felt a need to study and do well in school in order to make their parents proud, again suggesting a high PDI. These findings suggest that students are not willing or ready to challenge individuals they believed were knowledgeable and perceived as authority figures. Hence, the perception that learning is more about how to do rather than how to learn (Hofstede et al., 2010) is still prevalent among these students. Only the high achievers were willing to ask questions in class. Development of deep and critical thinking would be challenging for the rest of the students. Working in groups for them is not about development of ideas but more a resource for obtaining answers for their assignments.

Most of the students did not have a preference for male or female teachers, implying low MAS. However, the need for a good job in their future indicates a high MAS in terms of career advancement and earnings. They also perceived that both genders should be given equal opportunities for jobs and building careers.

These students studied in order to secure a better job in the future. This need for security was evident in their need to pass their examinations. This risk aversion would not help them develop deep learning (Biggs \& Tang, 2007) which is crucial for critical and analytical skills. They tended to memorise information which would keep them at the knowledge level. There was little contextual learning taking place which hindered the development of lifelong learning skills.

2. What are the differences in the influence of culture on high, average and low achieving students?

The results from the interviews of these students were analysed to determine the influence of culture on how and why these three groups learned. The results are shown in Table 2. 


\section{DISCUSSION}

All the students in the sample, regardless of their achievement levels as shown in Table 2, studied because they did not want to disappoint their parents. However, the average achievers also studied because they did not want to get in trouble with their parents and teachers. All of these students wanted a better job in future, but the three groups expressed this in different ways. The high achievers wanted a better career, implying they would have more work related responsibilities as time passed. In contrast, the average and low achievers, $80 \%$ and $100 \%$, respectively as shown in Table 2, studied because they wanted a job with better pay; hence, they were more interested in potential monetary gains. The average group, $80 \%$ of them, added that they wanted to be persons who are respected as shown in Table 2. The high achievers were the only ones who mentioned they liked and were happy to learn.

These students used similar approaches to learn regardless of their achievement levels as shown in Table 2. All the students went for after school tuition classes but for different reasons. The high achievers wanted extra help when preparing for the national examinations. The average achievers went to learn how to answer examination questions, while the low achievers went in order to keep up in school. The low achievers, $60 \%$ of them, preferred to study in a group so that their friends could help them with the work. About $70 \%$ of the average achievers studied in groups to share information and complete their work. All of the high achievers liked working in groups especially with challenging assignments that required research. There were also differences between the average and high achievers in how they learned. All of the high achievers listened and asked questions in class; whereas, about $75 \%$ of the average achievers would use the hints given by teachers to predict possible questions. All the low achievers only wanted to be taught what was covered in the examinations.

\section{CONCLUSION}

The results of this study suggest that the cultural backgrounds of students can influence the effectiveness of learning approaches. The growing need for education will further demand that learning must 
be a culturally adapted experience (Parrish \& Linder-VanBerschot, 2010). This is because students entering learning environments that are not aligned with their own culture can experience significant conflict. This conflict arises not only because of a difference in teaching and learning styles but also because of the struggle students will have in trying to maintain a connection with their local culture and their new learning environment. According to Parrish and Linder-VanBerschot (2010), this can influence their performance during the learning experience.

Furthermore, students need to be comfortable about making mistakes and learning from them in order to promote deep thinking (Biggs \& Tang, 2007). They also need to be open to exploring new ideas through group interaction. These students were reluctant risktakers as they took extra classes to hone their test-taking skills. Such classes only develop "test thinkers" (Maylone, 2004), a term used to describe the ability of students to behave in idiosyncratic ways while taking tests which are unconnected to content knowledge. "Test thinkers" often choose to memorise content rather than engage in deep thinking.

The process of learning could be enhanced if it is perceived as enjoyable (Seligman, 2002). However, these students were more interested in passing examinations than enjoying the learning process. They also viewed their teachers as sources of answers and information rather than as facilitators to help them learn, as suggested by Hofstede et al. (2010). The implementation of studentcentred learning will be challenging as these students are not willing to explore on their own. Based on the results, risk-taking behaviour is lacking among these students; hence, the willingness to experience failures which is important when developing deep thinking (Biggs, 1999) is absent.

The wish for a better job in future and low risk-taking behaviour seems to be contradictory. Employers value a certain amount of independence and willingness to take risks among their employees. These students were not keen on developing such skills. Hence, creating awareness among these students on the kinds of behaviours and skills required by employers is needed. Although this study has generated interesting information on learning among Malaysian students, the influences of culture need to be taken with caution. 
Although Hofstede (1984) has treated culture as something that is static, other researchers have suggested that it may be more fluid in nature (Signorinia, Wiesemesa, \& Murphya, 2009). Osland and Bird (2000) even warn against cultural stereotyping. They caution about the need for students to understand the complexities of their own culture and to use the various cultural stereotypes as basic tools to better understand themselves. If culture indeed plays a part in learning, it is necessary for students to make sense of their social environment and create an awareness of their own culture that would help them learn better.

This study generated many more questions than it answered. One question is on how to create awareness of the need to take risks. Another is the best approach to help these students accept that failure is part of learning. Skills training and learning for mastery need to be impressed upon them as well. Hence, further research into learning approaches and strategies must take into consideration the influence of culture on student behaviour in learning situations. One way of helping students gain awareness on the way they learn is by helping them gain insights into how they behave among their peers and in learning situations. Questionnaires that help generate this awareness can be developed.

\section{ACKNOWLEDGEMENTS}

We would like to acknowledge the contributions of Frances A. Bryant to the successful completion of this paper.

\section{REFERENCES}

Ahmad, A. Sahbak, R. (2009). Teacher-student attachment and teachers' attitudes towards work. Jurnal Pendidik dan Pendidikan, 24, 55-77.

Biggs, J. (1999). What the student does: Teaching for enhanced learning. Higher Education Reaserch and Development, 18 (1), 57-75.

Biggs, J., \& Tang, C. (2007). Teaching for quality learning at university: What the student does (3rd ed.). Berkshire: Open University Press. 
Creswell, J. W. (2013). Qualitative inquiry and research design: Choosing among five approaches. Los Angeles: Sage.

Ginsberg, M. B. (2005). Cultural diversity, motivation and differentiation. Theory into Practice, 44(3), 218-225.

Hiew, W. (2012). English language teaching and learning issues in Malaysia: Learners' perceptions via Facebook dialogue journal. Researchers World, 3(1), 11-19.

Hofstede, G. (1984). The cultural relativity of the quality of life concept. Academy of Management Review, 9 (3), 389-398.

Hofstede, G. (2001). Culture's consequence. London: Sage Publications.

Hofstede, G. (2007). A European in Asia. Asian Journal of Social Psychology, 10, 16-21.

Hofstede, G., Hofstede, G. J., \& Minkov, M. (2010). Cultures and organisations: Software of the mind. New York: McGraw-Hill.

Kember, D. ( 2000). Misconceptions about the learning approaches, motivation and study practices of Asian students. Higher Education, 40 (1), 99-121.

Kember, D., \& Wong, A. (2000). Implications for evaluation from a study of students' perceptions of good and poor teaching. Higher Education, 40(1), 69-97.

Khoo, H. E. (2003). Implementation of problem-based learning in Asian medical schools and students' perceptions of their experience. Medical Education, 37(5), 401-409.

Kluckhohn, C. (1962). The study of culture. In S. Tax, Anthropology today: Selections (pp. 304-320). Chicago: University Chicago Press.

Kuhnen, U., Hannover, B., Ute, R., Ashiq, A. S., Schubert, B., Upmeyer, A., et al. (2001). Cross-cultural variations iniIdentifying embedded figures comparisons from the United States, Germany, Russia, and Malaysia. Journal of CrossCultural Psychology, 32(3), 366-372.

Larkin, M., Watts, S., \& Clifton, E. (2006). Giving voice and making sense in interpretive phenomenological analysis. Qualitative research in Psychology, 3, 102-120.

Littlewood, W. (2001). Students' attitudes to classroom English learning: A cross-cultural study. Language Teaching Research, 5(1), 3-28.

Maylone, N. (2004). Do tests show more than 'test think'? The Education Digest, 69 (8), 16-20. 
Noordin, F., \& Jusoff, K. (2010). Individualisim-collectivism job satisfaction between Malaysia and Australia. International Journal of Educational Management, 24 (2), 159-174.

Parrish, P., \& Linder-VanBerschot, J. A. (2010). Cultural dimensions of learning: Addressing the challenges of multicultural instruction. The International Review of Research in Open and Distance Learning, 11 (2), 1-19.

Radnor, H. A. (2002). Researching your professional practice: Doing interpretive research in educational settings. London: Open University Press.

Seligman, M. (2002). Authentic happiness: Using the new positive psychology to realize your potential for lasting fulfilment. Boston: Simon and Schuster.

Vygotsky, L. (1986). Thought and language. Boston: The MIT Press.

Williams, M., \& Burden, R. L. (1997). Psychology for language learners. London: Cambridge University Press.

Zion, S., \& Kazleski, E. (2005). Understanding culture. Colorado: National Institute for Urban School Improvement. 